\title{
o Sul global pensado por mulheres do Sul global: agendas de pesquisa e enfoques de análise
}

\author{
The global South thought by women from the global South: research agendas and analysis approaches
}

DOI: https://doi.org/10.22456/2178-8839.117808

Lara Martim Rodrigues Selis

Universidade Federal de Uberlândia, Uberlândia, Brasil

laramrselis@gmail.com

Veronica Korber Gonçalves Universidade Federal do Rio Grande do Sul, Porto Alegre, Brasil

vkgoncalves@gmail.com

O que significa um enfoque do/no Sul global no estudo das Relações Internacionais? Ao percorrer os trabalhos desse Dossiê, múltiplos em suas perspectivas, a leitora poderá confirmar o aspecto ainda polifônico das respostas dadas àquele questionamento. A amplitude das aplicações do Sul global comporta desde alusões ao termo comolugar geográfico, como conceito, como categoria analítica, até sua utilização como símbolo, como escolha metodológica, dentre outras. Em comum, percebemos naquelas que mobilizam tal chave uma preocupação em demarcar uma postura crítica em relação às ontologias, às epistemologias e/ou às metodologias naturalizadas nas RI, e que, não raro, alinham -se ao enfoque "centrado no Ocidente", ou no Norte, compreendendo os países "desenvolvidos"; o lugar geográfico que compreende a América do Norte e Europa ocidental, suas agendas de pesquisa, narrativas e ferramentas teórico-analíticas.

Cabe explicitar, no entanto, que a relação Norte versus Sul não se refere a elementos estanques, e não respeita as suas coordenadas geográficas. Se tomado a partir das dinâmicas de poder, de hierarquização de formas de ver, viver e explicar o mundo, há Norte no Sul, Sul no Norte e, por que não, também o Sul do/no Sul global. Nesse sentido, "a pergunta interessante, não seria sobre onde está o Oeste ou o Sul, mas sim sobre o que se pode fazer com isso. Quais conhecimentos, subjetividades, e imaginários políticos tais designações cardinais evocam?"” (KRISTENSEN, 2021, p. 220, traduçãonossa). Acreditamos que os doze trabalhos reunidos neste Dossiê, fruto do convite realizado pelos editores da Revista Conjuntura Austral, respondem de formas férteis e distintas a essa provocaçãolançada por Kristensen.

Em um esforço de sistematização, os textos que compõem o dossiê podem ser compreendidos a partir de três linhas de abordagens: i) parte das contribuições versa sobre agendas de pesquisa e novos enquadramentos identificados por pesquisadoras como estando situadas no debate do Sul global; ii) parte trata, a partir de campos empíricos distintos, da questão da representatividade e da presença das mulheres em espaços da política; e, por fim iii) alguns trabalhos situam-se no debate feminista do Sul global para pensar (e propor novas formas de pensar) temas de Relações Internacionais.

${ }^{1}$ No original: "The interesting question, therefore, is not where the West or South is, but what you can do with it. What knowledge, subjectivities, and political imaginaries do cardinal designations evoke?" 
Os textos abordam aspectos não pretensamente universalizáveis, mas que dizem algo de/sobre as Relações Internacionais. De forma geral, os artigos chamam nossa atenção para como os corpos femininos (ou feminilizados) têm refletido sobre o campo, e mais, sobre como essa posicionalidade abre um espaço para a recolocação das perguntas e das agendas estudadas na disciplina. Assim, embora os trabalhos não esgotem ou encerrem todas as possibilidades de mulheres pensarem o Sul global, eles certamente apontam algumas tendências. A principal delas, ao nossover, remete ao deslocamento da gramática disciplinar, antes demasiadamente fundada em um sujeito descorporificado, quer seja na posição de autor ou de objeto, que passa então a ser redirecionada e tension ada pelo vocabulário de uma experiência não mais abstrata, mas corporal, histórica e relacional. Com isso, pensar temas clássicos do campo, como integração regional, violência, desenvolvimento, operações de paz, parcerias estratégicas, defesa, dentre outros, torna-se um exercício atravessado por questões de gênero, sexualidade, desigualdade, nacionalidade, etc.

Considerando os novos enquadramentos identificados pelas pesquisadoras, destacamos os artigos que abordam agendas que tensionam e retomam o Sul global, ora como conceito e categoria analítica, ora como geografia. No trabalho que abre nosso Dossiê, escrito por Ana Flávia Barros Platiau, Leandra Regina Gonçalves e Carina Costa Oliveira,o Sul Global está presente como espaço cujas dinâmicas particulares de poder tornam imperativo o debate sobre desigualdade de gênero também nas reflexões sobre Justiça azul. As autoras abordam o papel das mulheres nas ciências do mar, e na construção de uma economia dos oceanos voltada à sustentabilidadejusta e inclusiva. Na discussão elaborada por Bárbara Magalhães Teixeira, o sentido de Sul global segue atrelado à discussão das desigualdades, porém preocupado com a agenda do desenvolvimento. Partindo do debate decolonial, a autora relaciona subdesenvolvimento, extrativismo e exploração do ambiente noSul global e aborda alguns dos desafios desses limites estruturais para os países latino -americanos.

Considerando essa mobilização geográfica do termo, o trabalho de Jacqueline A. Haffner e Hetalben Haribhai Patel mobiliza o Sul global nas relações entre a Índia e Moçambique. Ao analisarem a parceria estratégica, as autoras engajam-se nas aproximações econômicas, políticas e de segurança entre os países e identificando uma parceria estratégica pouco explorada nos estudos da área. Também preocupada com um objeto pouco analisadono campo, Talita de Mello Pinottie Patricia Capelini Borelli propõem com seu trabalho traçar uma revisão sobre os posicionamentos da China nas operações de paz executadas pela ONU aolongo de mais de quatro décadas. O artigo de Mariana Pimenta Bueno inquieta-nos a pensar sobre o que escapa à noção de "universalidade" nas práticas e discursos envolvidos na conservação do patrimônio e da memória. Como vemos, neste e nos demais trabalhos do Dossiê, atentar-se para atores antes tomados como marginais configura-se um compromisso metodológico imprescindível para avaliar como as experiências políticas desses loci impactam as agendas tradicionais da área.

Com efeito, os trabalhos do dossiê caminham na esteira das produções que entendem a complexidade das relações de poder que atravessam as dinâmicas internacionais contemporâneas. Por exemplo, no texto de Beatriz Azevedo Coutinho, Laira Rocha Tenca e Cecília Soares Mombelli, debate-se como um vírus é capaz de transnacionalizar pautas sanitárias e revelar a falsa universalidade dos corpos, cujas experiências díspares descortinam as desigualdades de infra estruturas, das normas e do próprio valor das vidas humanas. A pandemia do COVID -19 também incita a discussão proposta por Silvia Lilian Ferro em relação às políticas públicas de cuidado em países do Mercosul, a partir do enfoque no cuidado como um conjunto de relações complexas e essenciais, mas invisibilizadas e desvalorizadas.

A transversalidade analítica fica clara tanto no trabalho de Carolina Pavese, como na pesquisa conduzida por Yetzy Urimar Villarroel Peña e Adriana Patricia Castaño Román, em que, respectivamente, aponta -se o impacto recíproco e combinado entre instituições regionais (UE e Mercosul) e a vida das mulheres, e a relação entre estruturas geopolíticas e a modulação das violências nacionais contra corpos femininos venezuelanos. Nesses exemplos, vemos como os artigos deste dossiê nos convidam a repensar nossas cartografias conceituais e analíticas a fim de dar conta das experiências heterogênease transversais do/no Sul global. 
Ainda no campo específico das experiências generificadas, alguns trabalhos mobilizam outro tema bastante caro aos estudos críticos e que está relacionado às ausências. Como bem afirmou Spivak, os trabalhos preocupados com lugares e vozes não hegemônicas devem assumir o compromisso metodológico de 'medir silêncios', considerando que em toda análise política "aquilo sobre o que o trabalho não pode falar tornar-se importante”2 (SPIVAK, 1988, p. 82). Com isso, destacamos o artigo escrito por Leticia González e Daniela Perrotta, e o trabalho produzido por Isabella Neumann e Graciela de Conti Pagliari Correio. Ambas as pesquisas buscam apresentar e refletir sobre os efeitos da aus ência ou do nãolugar das mulheres na política: uma tratando dos estudos de integração regional e o outra, da prática militar. Tratam-se de pesquisas urgentes na medida em que demonstram agendas por muito tempo ofuscadas pela prerrogativa androcêntrica presente nas teorias clássicas de RI. Por isso, recolocar a mulher como categoria analítica na disciplina tem sido um dos objetivos centrais dos esforços feministas no campo. Para além, as teóricas do Sul Global, adicionam a esta tarefa o desafio de pensar o feminismo a partir das experiências plurais das identidades definidas pelos marcadores sociais de diferença. Nessa esteira, e amparadas pelo debate pós -colonial, o trabalho de Sophia Teixeira e Souza e Julia Bertino Moreira encerra o dossiê chamando nossa atenção para a discussão feminista desde a perspectiva das mulheres árabes e mulçumanas.

Essa rede de agendas e perspectivas deixa clara a centralidade desse Dossiê como veículo para as pesquisas de excelência desenvolvidas pelas mulheres do campo. Cabe pontuar o papel da Revista Conjuntura Austral na divulgação de dados, argumentos e visões sobre espaços e identidades geralmente marginalizadas no campo, a exemplo das produções e discussões em torno da América Latina, da África e da Ásia. Assim, para além do presente dossiê, a Revista tem se dedicado a romper com a hegemonia, na área das Relações Internacionais, de artigos científicos publicados predominantemente em língua inglesa e cuja posição de enunciação e também objeto de estudo estejam estritamente vinculados ao Norte global.

Por outro lado, a despeito dos esforços, algumas desigualdades ainda precisam ser enfrentadas. Por exemplo, no campo específico das posicionalidades de gênero, dentre os mais de 300 artigos publicados na Conjuntura, verificamos que $60 \%$ deles são de autores homens contra $25 \%$ de artigos escritos apenas por mulheres. Certamente, não se trata de uma disparidade exclusiva da revista, visto que os dados ilustram um espaço reconhecidamente restrito ocupado por mulheres nas publicações acadêmicas da área, quer no Brasil ou no mundo. Uma pesquisa recente realizada entre os membros da Associação Brasileira de Relações Internacionais (ABRI) revelou um conjunto de desigualdades de gênero presentes ao longo de toda carreira acadêmica das participantes. Especificamente sobre a dimensão das publicações, o estudo aponta que " $66 \%$ das mulheres, contra 79\% dos homens, possuem mais de três publicados em periódicos indexados no sistema Qualis-Capes do Brasil” (BACCARINI; MINILLO; ALVES, 2019, p. 380 -381, tradução nossa). Dentre as razões apontadas na pesquisa para tal assimetria, destacamos as dificuldades derivadas da ordem patriarcal que induz uma sobrecarga de trabalho para as mulheres com relação à "economia do cuidado", em especial em contextos de m aternidade.

Vale pontuar que tais disparidades de gênero conformam uma situação global, como podemos ver na pesquisa realizada com base nos dados disponibilizados pelo projeto “Teaching, Research, and International Policy” (TRIP), cujo resultado aponta para a presença de um gender gap também no campo das citações acadêmicas. Segundo os autores do estudo, os artigos assinados por mulheres são sistematicamente menos citados na área, o que possivelmente se deve a dois fatores relacionados ao sexismo: “(1) as mulheres tendem a se citar menos do que os homens, e (2) os homens (que constituem uma parcela desproporcional dos acadêmicos de RI) tendem a citar mais homens do que mulheres" (MALINIAK; POWERS; WALTER, 2013, p.889, tradução nossa). Ou seja, para além das barreiras para entrada na carreira docente, nós mulheres temos também que lidar com o fato de nossas análises e resultados de pesquisa serem menos ouvidos, menos compartilhados, menos reconhecidos. Assimetrias também reforçadas pelas dinâmicas interligadas com raça, classe, origem e pertencimento institucional.

\footnotetext{
${ }^{2}$ No original: "the notion of what the work cannot say becomes important".
} 
Diante do baixo grau de engajamento das instituições acadêmicas na criação de políticas de promoção de igualdade de gênero, os mais variados processos de avaliação docente permanecem incapazes de reconhecer e reparar os contextos de disparidade mencionados. Ainda que não nos filiemos à defesa de uma perspectiva essencialista quanto a um “tipo específico" de olhar das mulheres, ou mesmo quanto a uma categorização fixa e restrita sobre essa posição identitária, o dossiê buscou compor um esforço maior de tornar o campo de produção e debate científico mais democrático. Com alegria, constatamos que seu lançamento coincide com a recente criação da Área Temática "Feminismos, Gênero e Sexualidade", aprovada no $8^{\circ}$ Encontro Nacional da ABRI, realizado em julho de 2021. Uma conquista histórica e imperativa para o campo das RI. Encerramos, então, essa introdução certas de que o dossiê ecoa uma comunidade de pesquisa engajada, em expansão e cuja potência produtiva nos reserva ainda muitas transformações necessárias.

\section{Referências}

BACCARINI, Mariana. P. O.; MINILLO, Xaman. K.; ALVES, Elia. E. C. Gender Issues in the Ivory Tower of Brazilian IR. Contexto Internacional, v. 41, p. 365-396, 2019.

KRISTENSEN, Peter Marcus. The South in "Global IR": Worlding Beyond the "Non-West" in the Case of Brazil. International Studies Perspectives, v. 22, n. 2, p. 218-239, 2021.

MALINIAK, Daniel.; POWERS, Ryan.; WALTER, Barbara F. The Gender Citation Gap in International Relations. International Organization, 67, 2013, p. 889-922.

SPIVAK, Gayatri C. Can the Subaltern Speak? Revised Edition. In: MORRIS, Rosalind C. (Ed.) Can the Subaltern Speak? Reflection on the history of an idea. Columbia University, 21-80, 2010. 